\title{
A Case of Decompensated Heart Failure Due to Prosthetic Valve Dysfunction: Quick Diagnosis with Fluoroscopy
}

\author{
Protez Kapak Disfoksiyonuna Bağlı Dekompanse Kalp Yetersizliği Olgusu: \\ Floro-skopi ile HızlıTanı
}

Ahmet Altuğ Çinçin, Beste Özben, Halil Ataş, Kürşat Tigen

Department of Cardiology, Marmara University Faculty of Medicine, İstanbul, Turkey

\section{ABSTRACT}

Introduction: Patients with decompensated heart failure due to prosthetic heart valves consists of a challenging group in emergency clinics for both diagnosis and treatment. Despite the important role in diagnosis, transthoracic echocardiography (TTE) remains unsatisfactory in many cases.

Case Report: A 65-year-old female patient with decompensated heart failure and a history of valve replacement surgery 6 years ago for both mitral and aortic valves was admitted. The diagnosis of prosthetic valve dysfunction was successfully fixed using fluoroscopy, despite the fact that initial TTE was not adequate enough to assess valve function.

Conclusion: In cases that TTE is not accessible or inadequate enough to assess valve function, fluoroscopy is a practical and quick method to rule out prosthetic valve dysfunction.

Keywords: Prosthetic valve dysfunction, pannus, fluoroscopy Received: 11.04.2015 Accepted:07.05.2015

Available Online Date: 12.06.2015

\section{ÖZET}

Giriş: Protez kapağı olup dekompanse kalp yetersizliği kliniği ile başvuran olgular, acil servislerde hem tanı hem de tedavi açısından zorlu bir grubu oluşturmaktadırlar. Bu hasta grubunda kapak fonksiyonlarının gösterilmesinde transtorasik ekokardiyografinin önemli rolü olsa da, yetersiz kaldığı durumlar sıktır.

Olgu Sunumu: Dekompanse kalp yetersizliği ile başvuran atmışbeş yaşındaki bayan hastanın 6 yıl önce mitral ve aortik kapak replasmanı hikayesi olduğu öğrenilmiştir. Kapak fonksiyonlarının değerlendirilmesinde transtorasik ekokardiyogafinin yeterli sonuç vermediği olgumuzda, floro-skopi cihazı kullanılarak kapak disfonksiyonuna başarılı bir şekilde tanı koyulabilmiştir.

Sonuç: Transtorasik ekokardiyografiye erişim sağlanamadığı veya yetersiz olduğu durumlarda, kapak disfonksiyonu ayırıcı tanısında ilk görüntüleme yöntemi olarak floro-skopi kullanılması pratik ve kesin bir yöntemdir.

Anahtar Kelimeler: Protez kapak disfonksiyonu, pannus, floro-skopi

Geliş Tarihi: 11.04.2015 Kabul Tarihi: 07.05.2015

Çevrimiçi Yayın Tarihi: 12.06.2015

\section{Giriş}

Protez kapağı olup dekompanse kalp yetersizliği kliniği ile başvuran olgular, acil servislerde hem tanı hem de tedavi açısından zorlu bir grubu oluşturmaktadırlar. Transtorasik ekokardiyografi birçok olguda dekompansasyonun gerçek sebebini ortaya koyabilse de, görüntü kısıtlılı̆ı olan hastalarda veya transtorasik ekokardiyografiye ulaşılamadığı durumlarda floro-skopi cihazı kullanılarak kapak yaprakçık hareketleri hızlı ve başarılı bir şekilde değerlendirilebilir. Transtorasik ekokardiyografinin yeterli sonuç vermediği benzer bir olguda skopi cihazı kullanılarak kapak disfonksiyonuna başarılı bir şekilde tanı koyulabilmiştir. 


\section{Olgu Sunumu}

Acil servise 1 aydır var olan, son 1 gündür belirginleşen nefes dar।ığı, çarpıntı şikayetleriyle başvuran 65 yaşında bayan hastanın 6 yıl önce romatizmal kalp kapak hastalığı nedeni ile aort ve mitral kapak replasmanı operasyonu hikayesi mevcuttu. Düzenli olarak varfarin 5 mg/gün, ramipril 10 mg/gün, furasemid 40mg/gün, metaprolol 25 mg/gün kullandığı öğrenilen hastanın, gelişinde kan basıncı 90/40 mmHg, solunum sayısı 28/dk, ateş $36,5^{\circ}$ oda havasında 5 It/dk O2 ihtiyacı olan hastanın fizik muayenesinde belirgin boyun venöz dolgunluğu ve bilateral orta zonlarda kadar ralleri mevcuttu. Mitral odakta metalik kapak sesleri duyulmakta iken aortik odakta sadece sistolik 2/6 üfürüm dikkat çekiciydi. Kliniği akciğer ödemi ile uyumlu bulunan hastanın INR düzeyi 4,3, proBNP'si >35000 pg/mL olarak ölçüldü. Yapılan transtorasik ekokardiyografide, orta-ileri aort yetersizlği, aortik kapakta belirgin gradyent artışı saptandı (Sahne 1, 2). Normal mitral kapak fonksiyonu saptanabilmiş olsa da, aortik kapak fonksiyonları net bir şekilde değerlendirilemedi.

Katater laboratuarında skopi eşliğinde alınan sine görüntülerde mitral protez kapak yaprakçıklarının tam fonksiyon gösterdiği, aortik protez yaprakçıklarının bir tanesinin tamamen hareketsiz, bir tanesinin ise belirgin derecede kısıtlı hareket ettiği görüldü (Resim 1, Sahne 3). Diüretik ağırlıklı medikal tedavi (furasemid $40 \mathrm{mg} / \mathrm{saat}$ infuzyon, enoksiparin 8000 Ünite) ile kliniği toparlayan ve oksijen ihtiyacı azalan hastanın izlemine koroner yoğun bakım ünitesinde devam edildi. Elektif şartlarda planlanan transösafegeal ekokardiyografisinde yaprakçık hareketlerini engelleyen patolojinin pannus ile uyumlu olduğu görüldü (Sahne 5, 6). Kardiyovasküler cerrahi kliniği ile birlikte değerlendirilerek kapağın replase edilmesine karar verildi.

\section{Tartışma}

Protez kapak disfonksiyonu, nadir görülen ancak hayatı tehtid edici niteliği olan bir durumdur (1). Bu komplikasyona yol çan iki en sık mekanizma kapak trombozu veya pannus oluşumudur. Genellikle kapak anulusundan orijin alan ve kapak içerisine doğru büyüme gösteren fibrotik doku pannus olarak adlandırımaktadır (2). Optimal antikoagulasyonun sağlanmadığı hastalarda daha sık karşılaşılan trombüse bağlı kapak disfonksiyonu hastaları daha akut semptomlarla başvururken, pannus nedeniyle oluşan kapak disfonksiyonları, sunulan vakada olduğu gibi zaman içerisinde kötüleşen semptomlarla başvururlar (3).
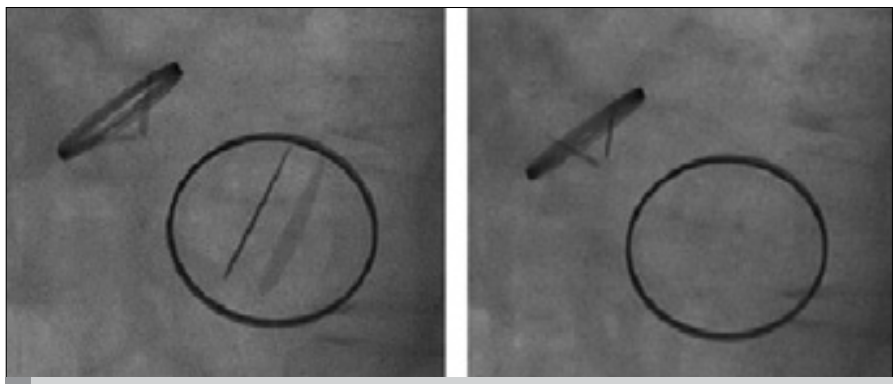

Şekil 1. Protez kapakların sine görüntüsü. Sistolde (a) ve diyastolde (b) aortik yaprakçık açıımı ve kapanması belirgin derecede kısıtlanmış.
Zaman içerisinde akım yönünde alan darlığı oluşturarak giderek artan gradyentlere sebep olan pannus, yaprakçık eklem bölgelerini tutarak hareketsiz hale getirdiğinde şiddetli semptom ve bulguların ortaya çıkmasına sebep olur. Acil servise kalp yetersizliği kliniği ile başvuran protez kapak olgularında ekokardiyografinin faydası tartışılmaz olmakla beraber aortik kapak fonksiyonlarının değerlendirilmesinde bir çok hastada yetersiz kalabilmektedir (4). Tıkayıcı olmayan kapak trombüsleri veya infektif endokardit gibi durumlar da benzer şekilde yetersizlik akımı, gradyent artışı veya her ikisi ile birlikte prezente olabilmektedir (5). Kapak disfonksiyonu varlığının gösterilmesi ise acil cerrahi tedavinin göz önünde tutulması açısından önemlidir.

\section{Sonuç}

Metalik protez kapak hikayesi olan ve kalp yetersizliği, senkop, ani ölüm, veya açıklanamayan semptomlarla başvuran hastalarda skopi ve sine görüntülerle kapak hareketlerinin değerlendirilmesi noninvaziv, hızlı, opak madde kullanımı gerektirmeyen, kolay ulaşılabilir bir yöntemdir. Transösafegeal ekokardiyografi aortik kapaktaki patolojinin ve disfonksiyon varlığının gösterilmesi için en kesin modalite olmakla beraber entübe edilmemiş hastalarda sedasyon gerekliliği, özellikli cihaz ve deneyimli kardiyoloji hekimi gerekliliği gibi sebeplerle acil şartlarda uygulanabilirliği kısıtlıdır. İlgili kılavuzda da belirtildiği üzere sine-floroskopi protez kapak disfoksiyonun gösterilmesinde etkili bir yöntemdir (6). Özelllikle transtorasik ekokardiyografi ile disfonksiyon varlığı açısından yeterli bilgi edinilemediği olgularda pratik bir yöntem olarak akılda tutulmalıdır.

Hasta Onamı: Bu çalışmaya katılan hastadan ve yakınlarından hasta onamı alınmıştır.

Hakem değerlendirmesi: Dış bağımsız.

Yazar Katkıları: Fikir - A.Ç.; Tasarım - A.Ç.; Denetleme - K.T.; Malzemeler - H.A.; Veri toplanması ve/veya işlemesi - A.Ç.; Analiz ve/veya yorum - A.Ç.; Literatür taraması - H.A.; Yazıyı yazan - A.Ç.; Eleştirel Inceleme - B.Ö.

Çıkar Çatışması: Yazarlar çıkar çatışması bildirmemişlerdir.

Finansal Destek: Yazarlar bu çalışma için finansal destek almadıklarını beyan etmişlerdir.

Informed Consent: Written informed consent was obtained from the patient and the patient's relatives who participated in this case.

Peer-review: Externally peer-reviewed.

Author Contributions: Concept - A.Ç.; Design - A.Ç.; Supervision - K.T.; Materials - H.A.; Data Collection and/or Processing - A.Ç.; Analysis and/or Interpretation - A.Ç.; Literature Review - H.A.; Writer - A.Ç.; Critical Review - B.Ö.

Conflict of Interest: The authors declared no conflict of interest.

Financial Disclosure: The authors declared that this study has received no financial support.

\section{Kaynaklar}

1. Roudaut R, Serri K, Lafitte S. Thrombosis of prosthetic heart valves: diagnosis and therapeutic considerations. Heart (British Cardiac Society) 2007; 93: 137-42. [CrossRef] 
2. Teshima H, Hayashida N, Yano H, Nishimi M, Tayama E, Fukunaga S, et al. Obstruction of st jude medical valves in the aortic position: histology and immunohistochemistry of pannus. J Thorac Cardiovasc Surg 2003; 126: 401-7. [CrossRef]

3. Ellensen VS, Andersen KS, Vitale N, Davidsen ES, Segadal L, Haaverstad R. Acute Obstruction by Pannus in Patients With Aortic MedtronicHall Valves: 30 years of Experience. Ann Thorac Surg 2013; 96: 2123-8. [CrossRef]

4. Montorsi P, De Bernardi F, Muratori M, Cavoretto D, Pepi M. Role of cinefluoroscopy, transthoracic, and transesophageal echocardiography in patients with suspected prosthetic heart valve thrombosis. Am J Cardiol 2000; 85: 58-64. [CrossRef]
5. Neragi-Miandoab S, Westbrook B, Flynn J, Blakely J, Baribeau Y. Prosthetic Valve Endocarditis Five Months following Transcatheter Aortic Valve Implantation and Review of Literature. Heart Surg Forum 2015; 18: E020-2. [CrossRef]

6. Vahanian A, Alfieri O, Andreotti F, Antunes MJ, Baron-Esquivias G, Baumgartner $\mathrm{H}$, et al; ESC Committee for Practice Guidelines (CPG); Joint Task Force on the Management of Valvular Heart Disease of the European Society of Cardiology (ESC); European Association for Cardio-Thoracic Surgery (EACTS). Guidelines on the management of valvular heart disease (version 2012): the Joint Task Force on the Management of Valvular Heart Disease of the European Society of Cardiology (ESC) and the European Association for Cardio-Thoracic Surgery (EACTS). Eur J Cardiothorac Surg 2012; 42: S1-44. [CrossRef] 